\title{
Synthetic Resveratrol Analogue, 3,3',4,4',5,5'-Hexahydroxy-trans-Stilbene, Accelerates Senescence in Peritoneal Mesothelium and Promotes Senescence-Dependent Growth of Gastrointestinal Cancers
}

\author{
Justyna Mikula-Pietrasik $^{1, \dagger}$, Patrycja Sosińska ${ }^{1, \dagger}$, Marcin Wierzchowski ${ }^{2}$, \\ Katarzyna Piwocka ${ }^{3}$ and Krzysztof Książek ${ }^{1}{ }^{1} *$
}

1 Laboratory of Gerontology, Department of Pathophysiology,

Poznań University of Medical Sciences, Święcickiego 6 Str., Poznań 60-781, Poland;

E-Mails: jmikum20@ump.edu.pl (J.M.-P.); psosinska@ump.edu.pl (P.S.)

2 Department of Chemical Technology of Drugs, Poznań University of Medical Sciences, Grunwaldzka 6, Poznań 60-780, Poland; E-Mail: mwierzch@ump.edu.pl

3 Laboratory of Cytometry, Nencki Institute of Experimental Biology, Polish Academy of Sciences, Pasteura 3, Warsaw 02-093, Poland; E-Mail: kpiwocka@nencki.gov.pl

$\dagger$ These authors contributed equally to this work.

* Author to whom correspondence should be addressed: E-mail: kksiazek@ump.edu.pl; Tel.: +48-618-546-579; Fax: +48-618-546-574.

Received: 26 August 2013; in revised form: 18 October 2013 / Accepted: 1 November 2013 / Published: 14 November 2013

\begin{abstract}
Hexahydroxy-trans-stilbene (M8) is a synthetic resveratrol derivative, advertised as a candidate drug highly effective against numerous malignancies. Because multiple tumors prone to M8 frequently metastasize into the peritoneal cavity, this study was aimed at establishing the effect of M8 on the growth and senescence of human peritoneal mesothelial cells (HPMCs), the largest cell population within the peritoneum, actively involved in the intraperitoneal spread of cancer. The study showed that M8, used at the highest non-toxic dose of $10 \mu \mathrm{M}$, impairs proliferation and accelerates senescence in cultured HPMCs via an oxidative stress-dependent mechanism. At the same time, soluble factors released to the environment by HPMCs that senesced prematurely in response to M8 promoted growth of colorectal and pancreatic carcinomas in vitro. These findings indicate that M8 may indirectly-through the modification of normal
\end{abstract}


(mesothelial) cells phenotype-facilitate an expansion of cancer cells, which challenges the postulated value of this stilbene in chemotherapy.

Keywords: cancer metastases; mesothelial cells; peritoneal cavity; replicative senescence; stilbenes

\section{Introduction}

Resveratrol (3,4',5-trihydroxy-trans-stilbene; RVT) is a prototype stilbene widely acknowledged for its anti-ageing properties. It has been found that RVT extends lifespan in various model organisms in vivo [1,2] as well as delays the onset of replicative senescence (a permanent withdrawal from the cell cycle after passing a certain number of divisions [3]) in cultured cells in vitro [4,5]. It is believed that these effects of RVT are mainly related to an induction of $\mathrm{NAD}^{+}$-dependent histone deacetylases, sirtuins, which control such vital cellular processes as energy homeostasis, maintenance of genetic stability, and stress response [6]. An another aspect of the RVT story which gained tons of attention over the past decade is its tumor-suppressing activity, associated with both anti-proliferative and pro-apoptotic effects exerted towards a wide range of malignancies [7,8].

Unfortunately, due to low bioavailability and successive breakdown to less active metabolites, the clinical value of RVT is limited. In order to avoid these restrictions, numerous modified (hydroxylated or methylated) derivatives of RVT were synthesized, and their activity is now being extensively investigated [9,10]. These studies are based on a paradigm that an introduction of additional groups into the stilbene structure strengthens biological properties of RVT analogues [11]. Of these newly synthesized derivatives, high expectations are linked with 3,3',4,4',5,5'-hexahydroxy-trans-stilbene (M8) which has been found to inhibit growth and/or induce apoptosis in various malignancies, including breast and colon cancers [12,13], leukemia [14], melanoma [15], and glioma cells [16] (Figure 1).

Figure 1. The chemical structure of stilbene M8 (3,3',4,4',5,5'-hexahydroxy-trans-stilbene). Additional hydroxy $(-\mathrm{OH})$ groups in the highly reactive position ortho are marked in the circles. The role of the ortho hydroxyl groups in the augmentation of some biological properties of resveratrol (RVT) derivatives has been explained in the discussion section.

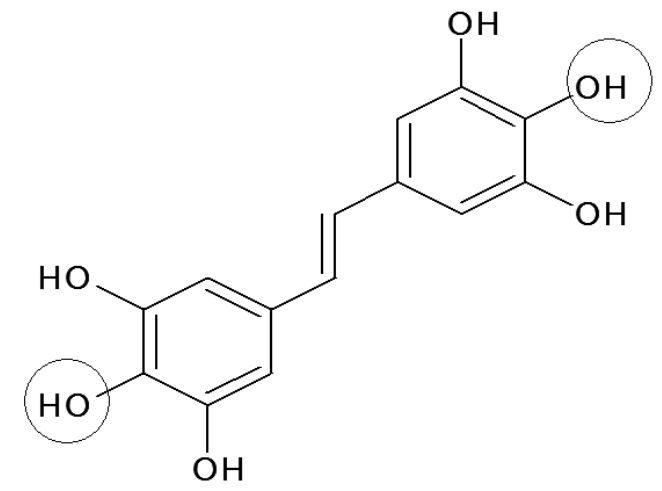


In some cases, the anti-tumor activity of M8 appeared to be even stronger compared with RVT itself $[17,18]$. It is believed that this increased cytotoxicity of M8 may be attributed to the presence of the ortho-hydroxyl groups in its structure which localisation is supposed to amplify several biological properties of the compound. One of the properties exacerbated by the additional ortho-hydroxyl groups is generation of mitochondrial reactive oxygen species (ROS), especially superoxides, whose deleterious activity may underlie either anti-proliferative or pro-apoptotic capabilities of M8 [19]. It should also be noticed that in some particular situations the biological effects exerted by M8 on processes involved in cancer progression may be entirely different-in terms of their direction, not a scale - from its natural precursor. This was the case, for instance, for the angiogenic behaviour of endothelial cells which upon exposure to M8 displayed increased effectiveness of proliferation and migration, conversely to RVT which inhibited both the processes [20].

The majority of cancers whose expansion was inhibited by M8 frequently metastasize into the peritoneal cavity [21,22], in which their further spread is controlled by a crosstalk with normal peritoneal mesothelium (HPMCs) [23]. As shown recently, the intraperitoneal cancer progression is facilitated by senescent HPMCs [24,25], which accumulate in the peritoneum in vivo [26].

Because M8 is advertised as a promising candidate for therapy of certain (also peritoneum-associated) tumors $[13,27]$ whose expansion usually increases with age, the goal of our study was to examine the effect of this stilbene on biological properties of HPMCs, particularly their proliferative potential and replicative senescence. In addition, we established a co-culture system in which we assessed whether soluble factors released to the environment by HPMCs subjected to M8 may modulate growth capabilities of ovarian, colorectal and pancreatic carcinomas.

\section{Results and Discussions}

\subsection{Stilbene M8 (3,3',4,4',5,5'-Hexahydroxy-trans-Stilbene) Impairs Viability of HPMCs}

(Human Peritoneal Mesothelial Cells) at the Doses Higher than $10 \mu \mathrm{M}$

In order to examine the effect of resveratrol analogue M8 on HPMC viability, confluent early-passage cells were exposed for $24 \mathrm{~h}$ to M8 in wide range of doses (from 0.1 to $100 \mu \mathrm{M}$ ), and then the MTT [3-(4,5-dimethylthiazol-2-yl)-2,5-diphenyltetrazolium bromide] reduction assay was performed. The experiments showed that stilbene M8 is non-toxic for HPMCs up to the concentration of $10 \mu \mathrm{M}$. At the greatest doses of M8, 50 and $100 \mu \mathrm{M}$, a significant cytotoxicity was recorded (Figure 2A). Because the concentration of $10 \mu \mathrm{M}$ appeared to be a threshold for sustained viability of HPMCs upon exposure to M8, additional tests were performed in which the cells were treated with this stilbene for seven days. Also in this case, however, the viability of cells exposed to M8 did not alter significantly from the values obtained for the control group (data not shown).

Accordingly, two final concentrations of M8 were chosen for all subsequent experiments. The first dose was $0.5 \mu \mathrm{M}$ which from one hand was entirely safe for HPMCs, and from the other hand appeared to efficiently stimulate growth and delay replicative senescence in HPMCs exposed to M8 precursor, resveratrol [5]. The second concentration was $10 \mu \mathrm{M}$ which seemed to be the safest for HPMCs in short-term and chronic experiments. 


\subsection{Stilbene M8 Inhibits Proliferation of Early-Passage HPMCs}

The impact of the stilbene M8 on cell proliferative capacity was assessed in short-term experiments using low-density cultures of early-passage HPMCs. As a measure of growth capabilities, the fraction of DNA replicating cells in the $S$ phase of the mitotic cycle and the percentage of cells expressing the S-phase specific proliferating cell nuclear antigen (PCNA) were quantified. The studies showed that $0.5 \mu \mathrm{M}$ M8 does not affect both the parameters associated with reproducibility of young HPMCs. At the same time, $10 \mu \mathrm{M}$ M8 reduced the magnitude of either the pool of cells in the S phase of the cell cycle (Figure 2B) or the subset of cells positive for PCNA antigen (Figure 2C,D).

Figure 2. Effect of M8 on viability and proliferation of early-passage human peritoneal mesothelial cells (HPMCs). Cell viability was examined using the MTT assay on the confluent cultures (A); Cell proliferative capacity was examined according to the measurements of cell distribution within the cell cycle, in particular in the $S$ phase (darkened area) (B); and the percentage of cells positive for proliferating cell nuclear antigen, PCNA $(\mathbf{C})$; The values shown in the panel B indicate the size of cell fraction in the $\mathrm{S}$ phase, in the control cells and the cultures exposed to $10 \mu \mathrm{M} \mathrm{M} 8$, respectively. Representative results of PCNA immunostaining in the control cells and the cultures exposed to $10 \mu \mathrm{M}$ M8 (D). PCNA-positive cells exhibit brown nuclei. All experiments were performed on cell cultures derived from the first passage and exposed to M8 at 0.5 and $10 \mu \mathrm{M}$ for $24 \mathrm{~h}$. The asterisks indicate a significant difference compared to the control group. Experiments were performed in triplicates with HPMC (human peritoneal mesothelial cells) cultures derived from 8-12 different donors.

A

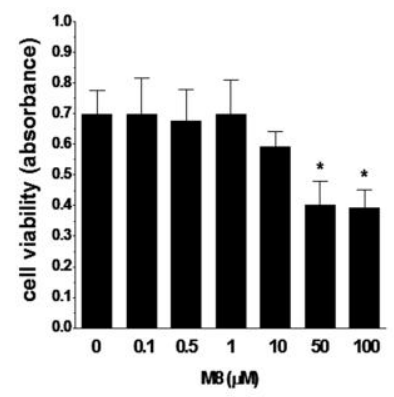

-

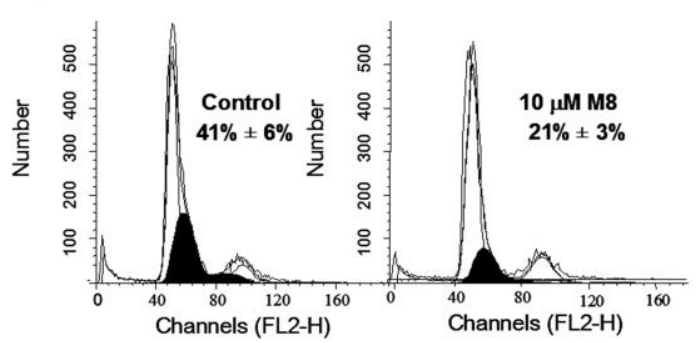

c

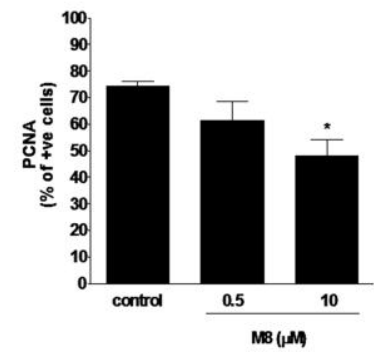

D

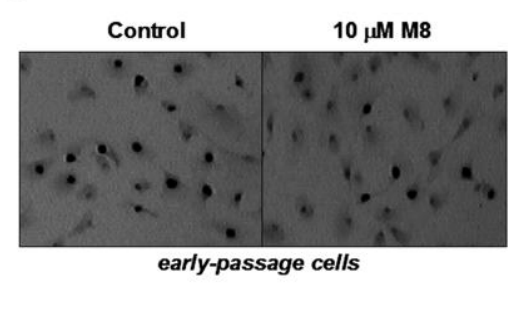




\subsection{Stilbene M8 Accelerates Senescence of HPMCs}

In order to answer the question of whether M8 affects the replicative lifespan of HPMCs, the cells were sub-cultivated at fixed seven-day intervals until complete cessation of their capacity to divide. Under such a regimen, the expandability of cells exposed to $0.5 \mu \mathrm{M}$ M8 was comparable to the control group. At the same time, when the cells were continuously propagated in the presence of $10 \mu \mathrm{M} \mathrm{M} 8$, their lifespan was reduced by a half (Figure 3A).

Rapid loss of cell ability to replicate and resulting premature entry into senescence of cells exposed $10 \mu \mathrm{M}$ M8 corresponded to increased activity of an indicatory enzyme for senescent cells, SA- $\beta$-Gal. Interestingly, up-regulated SA- $\beta$-Gal in cells subjected to $10 \mu \mathrm{M}$ M8 was also recorded in early-passage cultures (Figure 3B,C).

Figure 3. Effect of M8 on replicative senescence of HPMCs. Cells were forced to senescence by serial passaging at seven-day intervals, as described in the methods section, and then the cumulative number of population doublings (CPD) (A) and the activity of SA- $\beta$-Gal (B) were examined. A box in the panel (A) indicates the time-point at which M8-treated cells became senescent while the control cells still proliferated vigorously. The samples of conditioned medium were taken at this point and then used in the experiments shown in Figure 4. Representative results of early-passage HPMC staining for SA- $\beta$-Gal (positive cells have dark colour within the cytoplasm) (C). The asterisks indicate a significant difference compared to the control group. Experiments were performed in with HPMC cultures derived from 12 different donors.

A

B

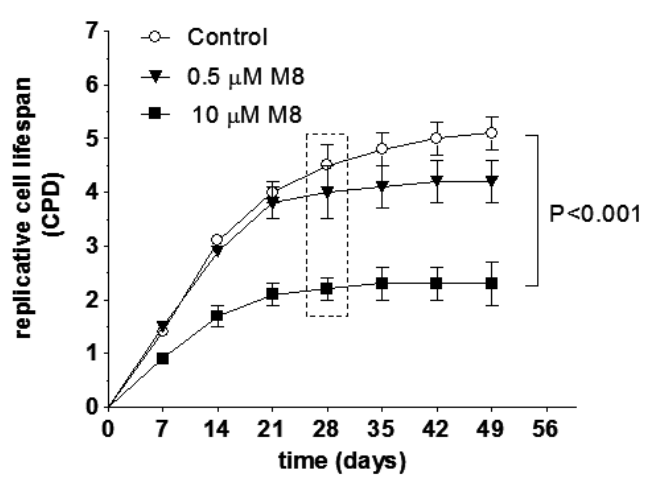

C
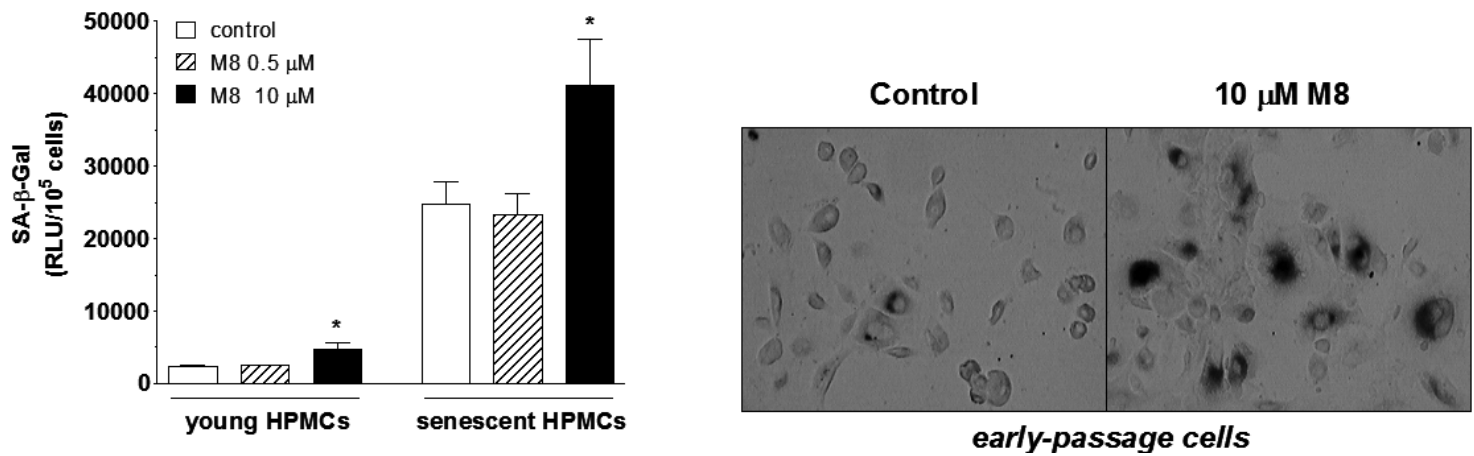


\subsection{Stilbene M8 Induces Oxidative Stress in Early-Passage and Senescent HPMCs}

Because senescence is considered as cell response to excessive DNA injury, a quantitative analysis of concentration of 8-OHdG (a major product of DNA oxidation) in cells subjected to M8 was performed. The results showed that the magnitude of oxidative DNA damage in cells treated with $0.5 \mu \mathrm{M}$ M8 remains unchanged. Conversely, in cells subjected to $10 \mu \mathrm{M}$ M8, concentration of 8 -OHdG was significantly higher compared with untreated control cells in both young and senescent cultures (Figure 4A,B).

Figure 4. The role of oxidative stress in M8-dependent premature senescence of HPMCs. The changes in 8-OHdG concentration in early-passage and senescent HPMCs subjected to M8 (A) as well as representative results of $8-\mathrm{OHdG}$ immunostaining (positive cells have dark nuclei) in early-passage cultures (B); The results of time-course experiments for reactive oxygen species (ROS) production (C) and superoxide dismutase (SOD) activity (D) in early-passage cells exposed to M8; The effect of ROS scavenger, $N$-tert-butyl- $\alpha$-phenylnitrone $(\mathrm{PBN}$, at $800 \mu \mathrm{M})$, on the activity of SA- $\beta$-Gal in cells treated with $10 \mu \mathrm{M}$ M8 (E). The cells were plated at a low density and then subjected to the stilbene for up to $72 \mathrm{~h}$. The asterisks indicate a significant difference compared to the control group while the symbol \# indicates a significant difference compared with M8-treated cells. Experiments were performed in duplicates with HPMCs derived from 8-10 different donors.

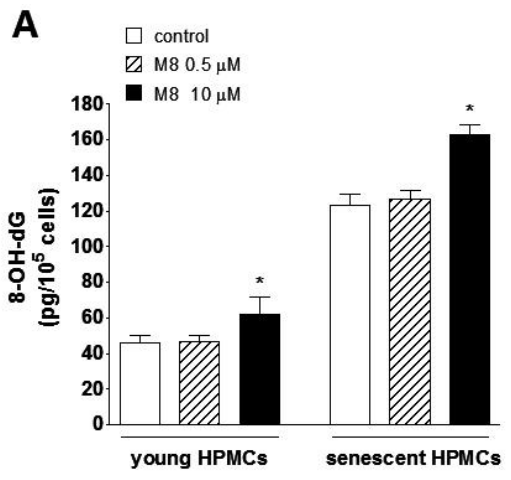

C

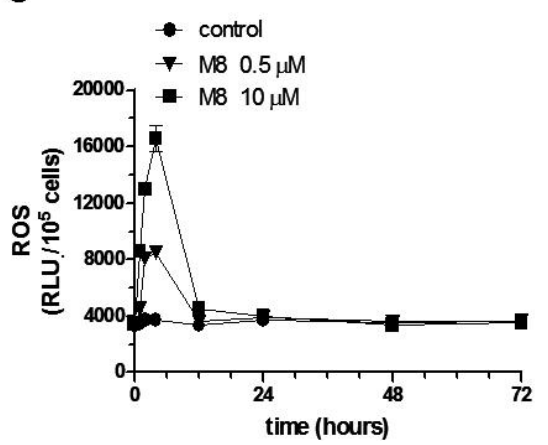

B

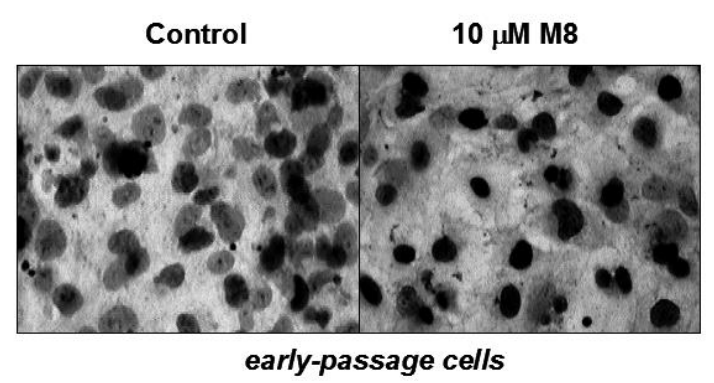

E

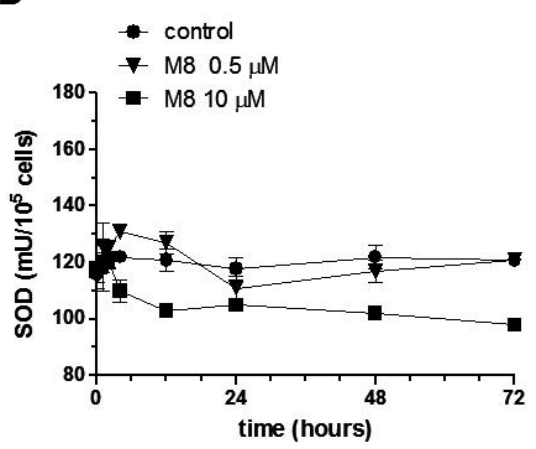

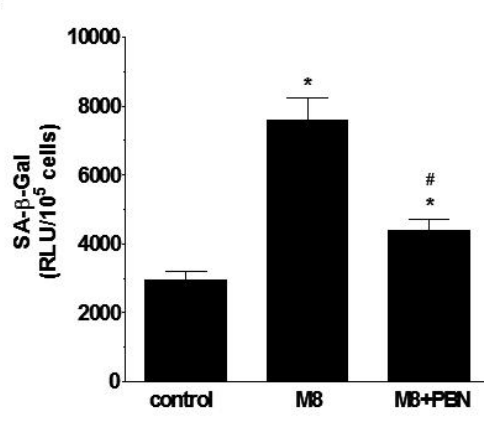


Afterwards, the time-course experiments on early-passage cells (derived from the first passage) were performed in order to examine the effect of M8 on two aspects of cellular oxidative stress; that is generation and neutralization [SOD (superoxide dismutase)-dependent] of reactive oxygen species (ROS). The experiments showed that cells subjected to M8 released ROS time-dependently with the highest value reached after the first $4 \mathrm{~h}$ of incubation. The magnitude of ROS production in cells exposed to $10 \mu \mathrm{M}$ M8 was at that moment twice as high as in cells exposed to $0.5 \mu \mathrm{M}$ stilbene. After reaching the peak value, ROS level rapidly declined and reached the baseline level at the $12 \mathrm{~h}$ of the experiment for the both concentrations of M8 (Figure 4C).

The simultaneous assessment of SOD activity revealed that in the cells subjected to $0.5 \mu \mathrm{M} \mathrm{M} 8$, after an elevation period taking $12 \mathrm{~h}$ (the peak at the $4 \mathrm{~h}$ ), it steadily decreased reaching the initial level. Conversely, in cells exposed to $10 \mu \mathrm{M}$ M8, SOD declined from the very beginning so that at the end of exposure it was substantially lower compared to the baseline values (Figure 4D).

In order to confirm if oxidative stress mediates premature senescence of HPMCs treated with M8, early-passage cells were exposed for $72 \mathrm{~h}$ to standard medium, to medium with $10 \mu \mathrm{M} \mathrm{M} 8$, and to medium with $10 \mu \mathrm{M}$ M8 enriched in a spin-trap ROS scavenger, $N$-tert-butyl- $\alpha$-phenylnitrone (PBN), used in the concentration of $800 \mu \mathrm{M}$ [26]. Afterwards, the activity of senescence marker SA- $\beta$-Gal was examined, and the results showed that the neutralization of ROS by simultaneous incubation with PBN significantly attenuated M8-mediated increase in SA- $\beta$-Gal activity (Figure 4E).

\subsection{Stilbene M8 Promotes Senescent HPMC-Dependent Growth of Cancer Cells}

Samples of conditioned medium (CM) harvested from HPMCs treated with M8 (at senescence-promoting dose of $10 \mu \mathrm{M}$ ) were used to examine growth response of cancer cells, metastasizing into peritoneal cavity. These included ovarian cancer (A2780), colorectal cancer (SW480), and pancreatic cancer (PSN-1). In these studies, CM from HPMCs propagated in standard growth medium collected at the time-point corresponding to senescence of M8-treated cells was used as the control. Cancer cell proliferation was assessed using the $\left[{ }^{3} \mathrm{H}\right]$-thymidine uptake assay, indicating the efficiency of DNA replication.

The experiments showed that both cancers of gastrointestinal origin exposed to CM from HPMCs that senesced prematurely under exposure to M8 displayed markedly improved DNA synthesis. In contrast, the proliferative behavior of ovarian cancer cells remained unchanged (Figure 5A). An increased efficacy of DNA replication in response to CM from M8-treated HPMCs also confirmed an analysis of cell distribution in the cell cycle, in particular the size of the fraction of cells in the $\mathrm{S}$ phase (Figure 5B). Further analysis of cell cycle positive regulators, cyclin D and cyclin E, using western-blot technique, revealed that cancer cell growth acceleration upon $10 \mu \mathrm{M}$ M8 was associated with significantly up-regulated expression of both $\mathrm{G}_{1}$ phase-specific cyclins (Figure 5C). 
Figure 5. Effect of M8 on HPMC-dependent proliferation of ovarian (A2780), colorectal (SW480), and pancreatic (PSN-1) cancer cells. Cell proliferation was assessed on low-density cultures exposed for $24 \mathrm{~h}$ to the conditioned medium harvested from HPMCs that senesced prematurely in response to $10 \mu \mathrm{M}$ M 8 and to the medium from the control cells (from the same passage), using $\left[{ }^{3} \mathrm{H}\right]$-thymidine incorporation assay (A); The measurements of cancer cell distribution within the cell cycle, in particular in the $S$ phase (darkened area) (B); The values shown in the panel (B) indicate the size of cell fraction in the $\mathrm{S}$ phase, in the cultures exposed to $\mathrm{CM}$ (conditioned medium) from control HPMCs and to $\mathrm{CM}$ from HPMCs prematurely senesced in response to $10 \mu \mathrm{M} \mathrm{M} 8$, respectively. The representative results of western-blot analysis of cell cycle regulators: cyclins D and E. Bands corresponding to target molecules were compared to those for GAPDH (C). The asterisks indicate a significant difference compared to the control cells treated as $100 \%$. The experiments were performed in quadruplicates with CM from HPMC cultures obtained from 5 different donors.

A
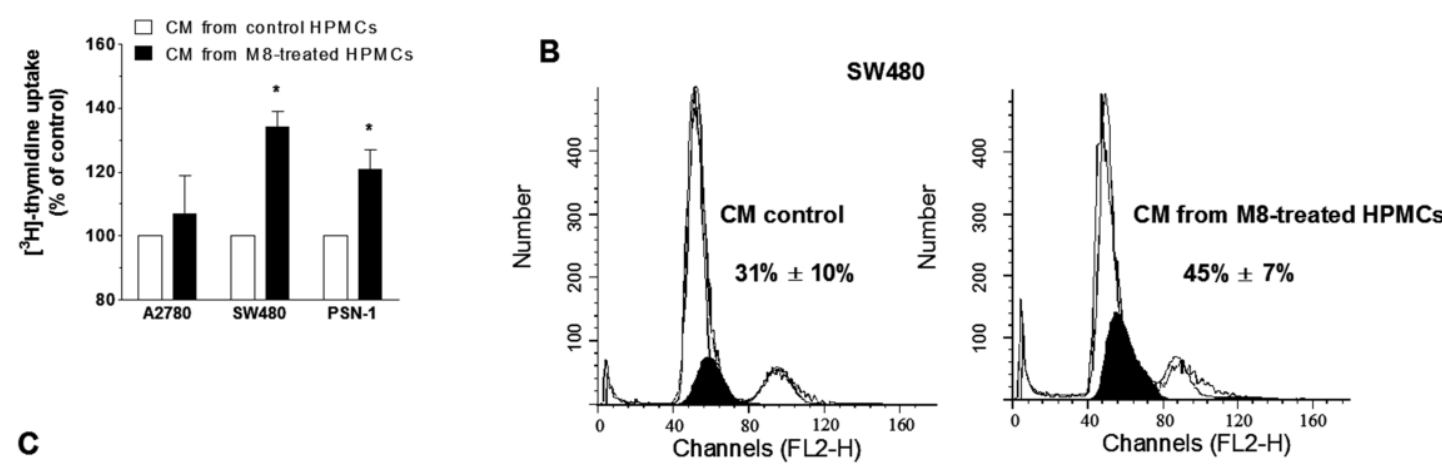

C
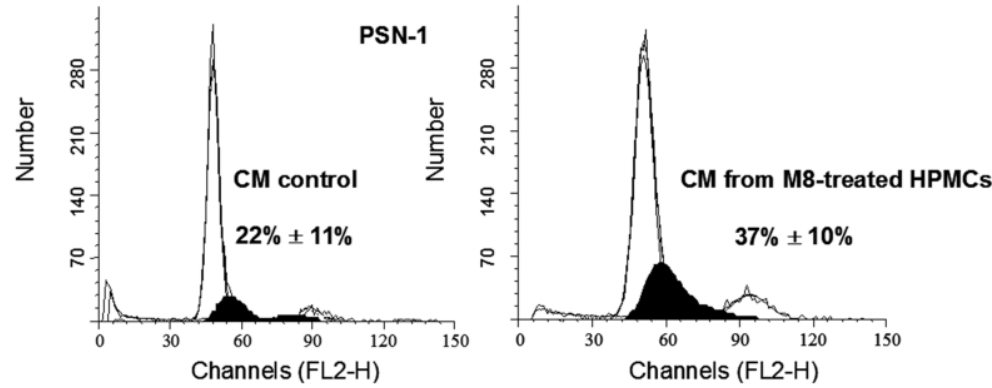

\subsection{Discussion}

A supreme anti-cancer drug should effectively stop an expansion of malignant cells without exerting any negative impact on biological properties of nearby normal cells. Most frequently, however, these bystanders become victims of chemotherapy which is usually linked with high doses of drugs which have to be used in order to guarantee a desirable effect. On the other hand, current studies aimed at establishing new classes of anti-cancer agents often skip (or at least underestimate) the crucial issue of a drug safety toward normal cells in regions encompassed by pathology. In some cases, such a simplistic approach may exert a paradoxical effect leading to enhanced tumor progression [28].

In this paper, we examined the effect of the synthetic resveratrol analogue M8 (recently postulated as an effective agent in a fight against multiple kinds of cancer cells [13,16,27]) on viability and 
proliferation of normal human peritoneal mesothelial cells (HPMCs) in vitro. The choice of HPMCs as an experimental model was dictated by the fact that the majority of carcinomas which appeared to be vulnerable to M8 has been found to disseminate in the peritoneal cavity, often in a HPMC-dependent mechanism [29-31]. Moreover, it has recently been shown that synthetic resveratrol derivatives, including M8, stimulate - in contrast to their natural precursor-HPMC-dependent angiogenesis [20], and thus may contribute to the development of a permissive microenvironment for intraperitoneal cancer spread.

Our current research showed that M8 is non-toxic for HPMCs only when it is used at a concentration up to $10 \mu \mathrm{M}$. At the same time, the measurements of young cell proliferation revealed that HPMC exposure to $10 \mu \mathrm{M}$ M8 markedly inhibited their growth (a lower concentration had no effect), as we evidenced analyzing the size of DNA-replicating cell fraction in the $\mathrm{S}$ phase of cell cycle and the subset of cells expressing S phase-specific proliferative marker, PCNA [32]. It must be stressed, however, that the dose of $10 \mu \mathrm{M}$ is relatively low, especially in the context of multiple studies on malignant cells in which M8 inhibited cell growth and/or triggered apoptosis. For instance, the proliferation assays performed on various types of breast cancer cells treated with M8 revealed that $\mathrm{IC}_{50}$ values for this stilbene range from 90 to $127 \mu \mathrm{M}$ [12]. In studies on melanoma cells, $\mathrm{IC}_{50}$ was between 20 and $25 \mu \mathrm{M}$ [15]. Similar tendency was reported in the case of apoptotic potency of M8 which achieved the values near to maximal (100\%) at the doses from 12.5 to $100 \mu \mathrm{M}$ [13].

Another aspect of HPMC behavior examined under exposure to M8 was cellular senescence. This process is of special importance in the context of cancer adhesion-promoting activity of senescent HPMCs which was recently documented with respect to ovarian, colorectal, and pancreatic cancers [24,25]. Here, we were able to show that M8 used at $10 \mu \mathrm{M}$ markedly shortens a long-term HPMC expandability which results in their premature entry into senescence (decreased number of divisions combined with increased activity of senescence marker, SA- $\beta$-Gal).

Because replicative senescence of HPMCs is primarily regulated by deleterious activity of ROS [26,33], we examined of whether M8 may accelerate an exhaustion of cell capacity to divide via increased oxidative stress. The experiments showed that, indeed, M8 markedly increases oxidative stress in HPMCs, as evidenced according to increased levels of oxidative DNA damage (8-OHdG) in early-passage and senescent HPMCs. This may be, in turn, attributed to an imbalance between up-regulated generation of ROS and decreased activity of antioxidative enzyme, SOD. An interesting issue is that ROS that peaked in the cells treated with M8 barely after few hours of exposure (and then returned to its baseline level) exerted its pro-senescence activity several days later which is in line with our previous observations that premature HPMC growth cessation depends to the largest extent on the deleterious activity of ROS (mainly DNA injury) experienced by the cells at the very early stages of their replicative history [26].

When it comes to an excessive ROS release in HPMCs subjected to M8, it is probably associated with the presence of two additional hydroxyl groups in a highly reactive position ortho in the stilbene structure (see Figure 1). The studies employing a microsomal model showed that the ortho compounds are able to form the cytotoxic semiquinones and thus stimulate additional oxygen consumption. This is possibly performed via redox cycling at expense of reducing equivalents transferred by cytochrome b5 and leads to augmented generation of ROS [19]. This scenario confirmed our previous studies which showed that the magnitude of ROS production by young and senescent HPMC upon treatment with 
M8 was significantly higher compared with other stilbenes possessing lower number of the ortho hydroxyl groups or not possessing them at all [20]. As for an insufficient antioxidative protection, our results are in keeping with those obtained by other groups and showing decreased activity of SOD and catalase in breast cancer cells treated with M8 [12]. The causative involvement of oxidative stress in premature senescence of HPMCs upon exposure to M8 confirmed experiments in which activity of senescence marker SA- $\beta-$ Gal in cells exposed to M8 was significantly attenuated in response to cell protection against ROS using the spin-trap scavenger PBN.

In order to verify a scenario in which HPMCs that senesced prematurely in response to M8 may facilitate cancer cell expansion, we used three cancer cell types whose adhesion was promoted by senescent HPMCs [24,25], and examined their growth response to soluble factors released to the environment by M8-treated HPMCs using M8- and serum-deprived conditioned medium. The results showed that the growth capabilities of colorectal and pancreatic (but not ovarian) carcinomas were markedly enhanced compared with the cells exposed to the medium from control cultures from the same passage. This, in turn, proves that the pro-senescence effect of M8 observed in vitro may be biologically relevant and may cause an improvement of HPMC-dependent progression of malignancy. From the mechanistic point of view, cancer growth acceleration was associated with an up-regulation of proteins positively controlling progression of cell cycle from the $G_{1}$ to $S$ phase, namely cyclins $D$ and $\mathrm{E}$ which was eventually reflected by increased fraction of cells in the $\mathrm{S}$ phase of cell cycle.

As for soluble HPMC-derived mediators of this phenomenon, VEGF and IL-8 may play a causative role, as they have an ability to directly or indirectly facilitate cancer cell proliferation [34,35], and their production by senescent HPMCs treated with M8 was markedly increased [20]. At the same time, it is puzzling why the conditioned medium obtained from HPMCs treated with M8 promoted exclusively the growth of gastrointestinal cancers but failed to affect proliferation of ovarian carcinoma. One may only speculate that this lack of effect may result from the different mechanisms of the reciprocal interactions between senescent HPMCs and those types of cancers, which have previously been documented with respect to their adhesion [24,25]. In addition, it cannot be ruled out that the effect we observed may be cell type-specific and related, e.g., to the differences in the expression of surface molecules between certain types of ovarian cancer cells [24,36]. Regardless, the exact reason for these differences should be identified.

\section{Experimental Section}

\subsection{Chemicals}

Unless otherwise stated, all chemicals and plastics were purchased from Sigma-Aldrich Corp. (St. Louis, MO, USA). 3,3',4,4',5,5'-hexahydroxy-trans-stilbene (M8) was synthesized in the Institute of Pharmaceutical Technology at the Poznań University of Medical Sciences (Poznań, Poland), using standard chemical procedures [37]. Stock solution of M8 was prepared in dimethyl sulfoxide (DMSO) and diluted in culture medium to desired final dose. 


\subsection{Cell Cultures}

Human peritoneal mesothelial cells (HPMCs) were isolated from the pieces of omentum. The tissues were obtained from consenting patients undergoing abdominal surgery. The study was approved by the institutional ethics committee. The cells were propagated in M199 medium enriched with L-glutamine $(2 \mathrm{mM})$, penicillin $(100 \mathrm{U} / \mathrm{mL})$, streptomycin $(100 \mu \mathrm{g} / \mathrm{mL})$, and $10 \%$ fetal bovine serum (FBS). During the experiments, the cells were continuously exposed to standard medium (control) and to the medium supplemented with M8 (at indicated doses). The culture media were exchanged every three days. Senescence of HPMCs was induced by serial passaging until exhaustion of cell replicative capacity. Cultures were considered "senescent" when they stopped divide, displayed hypertrophic morphology, and more than $70 \%$ of the population stained positively for SA- $\beta-$ Gal [26]. Cells harvested after seven days of incubation (during first passage) were considered "young".

Ovarian cancer cells (A2780) and pancreatic cancer cells (PSN-1) were obtained from the European Collection of Cell Cultures (Porton Down, UK). Colorectal cancer cell line SW480 was purchased from the American Type Culture Collection (Rockville, MD, USA). All cancers were propagated in RPMI-1640 medium supplemented with $10 \%$ fetal bovine serum (FBS).

\subsection{Determination of Cell Viability}

Cells were seeded into 96-well plates at a high density of $1 \times 10^{5}$ cells $/ \mathrm{cm}^{2}$ and allowed to attach for $16 \mathrm{~h}$. Then cells were incubated in medium containing $1.25 \mathrm{mg} / \mathrm{mL}$ of the MTT salt [3-(4,5-dimethylthiazol-2-yl)-2,5-diphenyltetrazolium bromide] for $4 \mathrm{~h}$ at $37{ }^{\circ} \mathrm{C}$. The formazan product generated was solubilized with $20 \%$ sodium dodecyl sulphate and $50 \% \mathrm{~N}, \mathrm{~N}$-dimethylformamide. Absorbance of the converted dye was recorded at $595 \mathrm{~nm}$ with a reference wavelength of $690 \mathrm{~nm}$.

\subsection{Cell Cycle Analysis}

Cells were harvested with trypsin-EDTA solution and fixed in ice-cold $70 \%$ ethanol overnight at $-20{ }^{\circ} \mathrm{C}$. After washing with PBS, cells were re-suspended in $0.1 \mathrm{M}$ sodium citrate, $\mathrm{pH} 7.8$ for $1 \mathrm{~min}$, and incubated for $30 \mathrm{~min}$ in PBS containing $5 \mathrm{mg} / \mathrm{mL}$ of propidium iodide (Molecular Probes, Eugene, OR, USA) and $0.1 \mathrm{mg} / \mathrm{mL}$ of RNase A. In order to determine cell distribution in the cell-cycle, one million cells was analyzed using a FACSCalibur ${ }^{\mathrm{TM}}$ flow cytometer with ModFit LT $^{\mathrm{TM}}$ software (Verity Software House, Topsham, ME, USA).

\subsection{Immunocytochemistry for Proliferating Cell Nuclear Antigen (PCNA)}

HPMCs were cultured in Lab-Tek ${ }^{\mathrm{TM}}$ Chamber Slides (Nunc, Roskilde, Denmark), fixed with $70 \%$ ethanol, and probed with specific anti-PCNA monoclonal antibody (clone PC10; Dako, Glostrup, Denmark), diluted 1:500. Bound antibodies were detected by immunoperoxidase staining using the EnVision System (Dako). 


\subsection{Detection of Senescence-Associated $\beta$-Galactosidase (SA- $\beta$-Gal)}

Activity of SA- $\beta$-Gal was quantified in cell extracts by measuring the rate of conversion of 4-methylumbelliferyl- $\beta$-D-galactopiranose to 4-methylumbelliferone, and recorded using spectrofluorometer Wallac Victor 2 (Perkin-Elmer, Waltham, MA, USA) with excitation at $360 \mathrm{~nm}$ and emission at $465 \mathrm{~nm}$. Expression of SA- $\beta$-Gal was also visualized cytochemically upon exposure (for $6 \mathrm{~h}$ at $37{ }^{\circ} \mathrm{C}$ ) to $1 \mathrm{mg} / \mathrm{mL}$ 5-bromo-4-chloro-3-indolyl- $\beta$-D-galactopyranoside (X-Gal), $5 \mathrm{mM}$ potassium ferrocyanide, $5 \mathrm{mM}$ potassium ferricyanide, $150 \mathrm{mM} \mathrm{NaCl}, 2 \mathrm{mM} \mathrm{MgCl}{ }_{2}$ and $40 \mathrm{mM}$ citric acid, at $\mathrm{pH} 6.0$.

\subsection{Measurements of Oxidative Stress-Related Parameters}

Production of reactive oxygen species (ROS) was assessed in cells probed with a fluorescent dye 2',7'-dichlorodihydrofluorescein diacetate ( $\mathrm{H}_{2} \mathrm{DCFDA}$, Molecular Probes). The fluorescence generated was monitored in a spectrofluorometer Wallac Victor 2 (Perkin-Elmer) with excitation at $485 \mathrm{~nm}$ and emission at $535 \mathrm{~nm}$. Activity of SOD was measured in cell extracts using a commercially available kit (R\&D Systems Europe, Abingdon, UK). Concentration of 8-hydroxy-2'-deoxyguanosine (8-OHdG) was assessed with a competitive immunoassay (Cell Biolabs Inc., San Diego, CA, USA). In some experiments, 8-OHdG was visualized immunocytochemically with monoclonal anti-8-OHdG antibody (Trevigen, Gaithersburg, MD, USA), diluted 1:300.

\subsection{HPMC-Derived Conditioned Medium}

Samples of conditioned media (CM) were harvested from HPMC cultures reaching senescence in the presence of M8, and from the corresponding control cells at the same passage. Briefly, when the cells exposed to M8 became senescent, both groups of cells were carefully washed with PBS to remove M8 and the serum, trypsinized, and counted. Afterwards $3 \times 10^{5}$ cells was seeded into $25 \mathrm{~cm}^{3}$ flasks, allowed to attach for $4 \mathrm{~h}$, and incubated in fresh serum-free medium for $72 \mathrm{~h}$. The samples of $\mathrm{CM}$ collected were centrifuged, filtered through a $0.2 \mu \mathrm{m}$ pore size filter to remove any cellular debris, and then stored in aliquots at $-80{ }^{\circ} \mathrm{C}$ until required.

\subsection{Cancer Cell Proliferation Measurements}

Cancer cell proliferation was examined according to an incorporation of $\left[{ }^{3} \mathrm{H}\right]$-thymidine into DNA of dividing cells. Briefly, cancer cells were plated onto 48 -well clusters at a density of $1.5 \times 10^{3}$ cells per well and allowed to attach for $2 \mathrm{~h}$. Then, the cells were growth synchronized by serum deprivation for $4 \mathrm{~h}$. Next, cells were exposed to HPMC-derived conditioned media for $24 \mathrm{~h}$ in the presence of $\left[{ }^{3} \mathrm{H}\right]$-thymidine (as methyl- $\left[{ }^{3} \mathrm{H}\right]$-thymidine; $1 \mu \mathrm{Ci} / \mathrm{mL}$; Institute of Radioisotopes, Prague, Czech Republic). After the incubation the cells were harvested with a trypsin-EDTA $(0.05 \%-0.02 \%)$ solution and precipitated with $10 \%(w / v)$ trichloroacetic acid (TCA). The precipitate was dissolved in $0.1 \mathrm{~N} \mathrm{NaOH}$ and the released radioactivity was measured in a $\beta$ liquid scintillation counter (Wallac, Perkin Elmer, Warsaw, Poland). The results obtained were normalized per number of HPMCs that gave rise to the conditioned medium at a particular passage [38]. In order to sensitize cancer cells to HPMC-specific 
conditioned medium, A2780, SW480 and PSN-1 cells were exposed to M199 medium for two weeks before the scheduled experiment.

\subsection{Western Blotting for Cell Cycle Regulators}

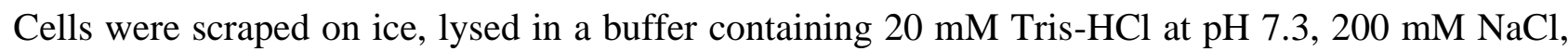
$1 \mathrm{mM}$ EDTA, 1\% Triton X-100, $1 \mathrm{mM}$ PMSF, and protease inhibitor cocktail (Roche Diagnostics, Mannheim, Germany), and homogenized by sonication. Samples corresponding to $40 \mu \mathrm{g}$ protein were resolved by $15 \%$ SDS-PAGE and transferred to Immobilon-P polyvinylidene difluoride membranes (Millipore, Eschborn, Germany). The membranes were blocked with 5\% non-fat powdered milk and probed with antibodies against either p16, p21, p53, cyclin D, cyclin E or GAPDH (Santa Cruz Biotechnology, Santa Cruz, CA, USA). Bound antibodies were visualized following incubation with the peroxidase-labeled secondary antibodies (Dako) and the exposure to chemiluminescence reagent (ECL; Amersham Pharmacia Biotech, Castle Hill, Australia).

\subsection{Statistics}

Statistical analysis was performed using GraphPad Prism ${ }^{\text {TM }} 5.00$ software (GraphPad Software, San Diego, CA, USA). The means were compared with repeated measures analysis of variance (ANOVA) with the Newman-Keuls test as post-hoc. When appropriate, the two-way ANOVA and Wilcoxon matched pairs test were used. Results were expressed as means \pm SEM. Differences with a $p$-value $<0.05$ were considered to be statistically significant.

\section{Conclusions}

Altogether, our results show that the clinical usefulness of the stilbene M8 in the anti-cancer therapy is seriously jeopardized by its HPMC senescence-promoting activity. In addition, they justify a verification of any promising effects obtained for anti-cancer drug candidates using normal nearby cells which, under certain conditions, may exert paradoxical cancer-promoting activity.

\section{Acknowledgments}

The study was supported by the grant from the National Science Center (decision number DEC-2011/03/N/NZ7/06277) for J.M.-P. and K.K.

\section{Conflicts of Interest}

The authors declare no conflict of interest.

\section{References}

1. Howitz, K.T.; Bitterman, K.J.; Cohen, H.Y.; Lamming, D.W.; Lavu, S.; Wood, J.G.; Zipkin, R.E.; Chung, P.; Kisielewski, A.; Zhang, L.L.; et al. Small molecule activators of sirtuins extend Saccharomyces cerevisiae lifespan. Nature 2003, 425, 191-196. 
2. Wood, J.G.; Rogina, B.; Lavu, S.; Howitz, K.; Helfand, S.L.; Tatar, M.; Sinclair, D. Sirtuin activators mimic caloric restriction and delay ageing in metazoans. Nature 2004, 430, 686-689.

3. Campisi, J. Senescent cells, tumor suppression, and organismal aging: Good citizens, bad neighbors. Cell 2005, 120, 513-522.

4. Giovannelli, L.; Pitozzi, V.; Jacomelli, M.; Mulinacci, N.; Laurenzana, A.; Dolara, P.; Mocali, A. Protective effects of resveratrol against senescence-associated changes in cultured human fibroblasts. J. Gerontol. A Biol. Sci. Med. Sci. 2011, 66, 9-18.

5. Mikula-Pietrasik, J.; Kuczmarska, A.; Rubis, B.; Filas, V.; Murias, M.; Zielinski, P.; Piwocka, K.; Ksiazek, K. Resveratrol delays replicative senescence of human mesothelial cells via mobilization of antioxidative and DNA repair mechanisms. Free Radic. Biol. Med. 2012, 52, 2234-2245.

6. Marques, F.Z; Markus, M.A.; Morris, B.J. Resveratrol: Cellular actions of a potent natural chemical that confers a diversity of health benefits. Int. J. Biochem. Cell Biol. 2009, 41, 2125-2128.

7. Smoliga, J.M.; Baur, J.A.; Hausenblas, H.A. Resveratrol and health-A comprehensive review of human clinical trials. Mol. Nutr. Food Res. 2011, 55, 1129-1141.

8. Aggarwal, B.B.; Bhardwaj, A.; Aggarwal, R.S.; Seeram, N.P.; Shishodia, S.; Takada, Y. Role of resveratrol in prevention and therapy of cancer: Preclinical and clinical studies. Anticancer Res. 2004, 24, 2783-2840.

9. Belleri, M.; Ribatti, D.; Nicoli, S.; Cotelli, F.; Forti, L.; Vannini, V.; Stivala, L.A.; Presta, M. Antiangiogenic and vascular-targeting activity of the microtubule-destabilizing trans-resveratrol derivative 3,5,4'-trimethoxystilbene. Mol. Pharmacol. 2005, 67, 1451-1459.

10. Kimura, Y.; Sumiyoshi, M.; Baba, K. Antitumor activities of synthetic and natural stilbenes through antiangiogenic action. Cancer Sci. 2008, 99, 2083-2096.

11. Fulda, S. Resveratrol and derivatives for the prevention and treatment of cancer. Drug Discov. Today 2010, 15, 757-765.

12. Murias, M.; Luczak, M.W.; Niepsuj, A.; Krajka-Kuzniak, V.; Zielinska-Przyjemska, M.; Jagodzinski, P.P.; Jager, W.; Szekeres, T.; Jodynis-Liebert, J. Cytotoxic activity of $3,3^{\prime}, 4,4$ ',5,5'-hexahydroxystilbene against breast cancer cells is mediated by induction of p53 and downregulation of mitochondrial superoxide dismutase. Toxicol. In Vitro 2008, 22, 1361-1370.

13. Saiko, P.; Horvath, Z.; Murias, M.; Handler, N.; Jaeger, W.; Erker, T.; Fritzer-Szekeres, M.; Szekeres, T. Antitumor effects of 3,3',4,4',5,5'-hexahydroxystilbene in HL-60 human promyelocytic leukemia cells. Nucleosides Nucleotides Nucleic Acids 2006, 25, 1013-1017.

14. Ovesna, Z.; Kozics, K.; Bader, Y.; Saiko, P.; Handler, N.; Erker, T.; Szekeres, T. Antioxidant activity of resveratrol, piceatannol and 3,3',4,4',5,5'-hexahydroxy-trans-stilbene in three leukemia cell lines. Oncol. Rep. 2006, 16, 617-624.

15. Paulitschke, V.; Schicher, N.; Szekeres, T.; Jager, W.; Elbling, L.; Riemer, A.B.; Scheiner, O.; Trimurtulu, G.; Venkateswarlu, S.; Mikula, M.; et al. 3,3',4,4',5,5'-Hexahydroxystilbene impairs melanoma progression in a metastatic mouse model. J. Invest. Dermatol. 2010, 130, 1668-1679.

16. Ruweler, M.; Gulden, M.; Maser, E.; Murias, M.; Seibert, H. Cytotoxic, cytoprotective and antioxidant activities of resveratrol and analogues in C6 astroglioma cells in vitro. Chem. Biol. Interact. 2009, 182, 128-135. 
17. Horvath, Z.; Murias, M.; Saiko, P.; Erker, T.; Handler, N.; Madlener, S.; Jaeger, W.; Grusch, M.; Fritzer-Szekeres, M.; Krupitza, G.; et al. Cytotoxic and biochemical effects of 3,3',4,4',5,5'-hexahydroxystilbene, a novel resveratrol analog in HL-60 human promyelocytic leukemia cells. Exp. Hematol. 2006, 34, 1377-1384.

18. Horvath, Z.; Marihart-Fazekas, S.; Saiko, P.; Grusch, M.; Ozsuy, M.; Harik, M.; Handler, N.; Erker, T.; Jaeger, W.; Fritzer-Szekeres, M.; et al. Novel resveratrol derivatives induce apoptosis and cause cell cycle arrest in prostate cancer cell lines. Anticancer Res. 2007, 27, 3459-3464.

19. Murias, M.; Jager, W.; Handler, N.; Erker, T.; Horvath, Z.; Szekeres, T.; Nohl, H.; Gille, L. Antioxidant, prooxidant and cytotoxic activity of hydroxylated resveratrol analogues: Structure-activity relationship. Biochem. Pharmacol. 2005, 69, 903-912.

20. Mikula-Pietrasik, J.; Kuczmarska, A.; Kucinska, M.; Murias, M.; Wierzchowski, M.; Winckiewicz, M.; Staniszewski, R.; Breborowicz, A.; Ksiazek, K. Resveratrol and its synthetic derivatives exert opposite effects on mesothelial cell-dependent angiogenesis via modulating secretion of VEGF and IL-8/CXCL8. Angiogenesis 2012, 15, 361-376.

21. Low, R.N. MR imaging of the peritoneal spread of malignancy. Abdom. Imaging 2007, 32, $267-283$.

22. Jayne, D.G.; Fook, S.; Loi, C.; Seow-Choen, F. Peritoneal carcinomatosis from colorectal cancer. Br. J. Surg. 2002, 89, 1545-1550.

23. Sodek, K.L.; Murphy, K.J.; Brown, T.J.; Ringuette, M.J. Cell-cell and cell-matrix dynamics in intraperitoneal cancer metastasis. Cancer Metastasis Rev. 2012, 31, 397-414.

24. Ksiazek, K.; Mikula-Pietrasik, J.; Korybalska, K.; Dworacki, G.; Jorres, A.; Witowski, J. Senescent peritoneal mesothelial cells promote ovarian cancer cell adhesion: The role of oxidative stress-induced fibronectin. Am. J. Pathol. 2009, 174, 1230-1240.

25. Ksiazek, K.; Mikula-Pietrasik, J.; Catar, R.; Dworacki, G.; Winckiewicz, M.; Frydrychowicz, M.; Dragun, D.; Staniszewski, R.; Jorres, A.; Witowski, J. Oxidative stress-dependent increase in ICAM-1 expression promotes adhesion of colorectal and pancreatic cancers to the senescent peritoneal mesothelium. Int. J. Cancer 2010, 127, 293-303.

26. Ksiazek, K.; Mikula-Pietrasik, J.; Jorres, A.; Witowski, J. Oxidative stress-mediated early senescence contributes to the short replicative life span of human peritoneal mesothelial cells. Free Radic. Biol. Med. 2008, 45, 460-467.

27. Saiko, P.; Pemberger, M.; Horvath, Z.; Savinc, I.; Grusch, M.; Handler, N.; Erker, T.; Jaeger, W.; Fritzer-Szekeres, M.; Szekeres, T. Novel resveratrol analogs induce apoptosis and cause cell cycle arrest in HT29 human colon cancer cells: Inhibition of ribonucleotide reductase activity. Oncol. Rep. 2008, 19, 1621-1626.

28. Klink, J.C.; Tewari, A.K.; Masko, E.M.; Antonelli, J.; Febbo, P.G.; Cohen, P.; Dewhirst, M.W.; Pizzo, S.V.; Freedland, S.J. Resveratrol worsens survival in SCID mice with prostate cancer xenografts in a cell-line specific manner, through paradoxical effects on oncogenic pathways. Prostate 2013, 73, 754-762.

29. Ahmed, N.; Riley, C.; Rice, G.; Quinn, M. Role of integrin receptors for fibronectin, collagen and laminin in the regulation of ovarian carcinoma functions in response to a matrix microenvironment. Clin. Exp. Metastasis 2005, 22, 391-402. 
30. Gardner, M.J.; Catterall, J.B.; Jones, L.M.; Turner, G.A. Human ovarian tumour cells can bind hyaluronic acid via membrane CD44: A possible step in peritoneal metastasis. Clin. Exp. Metastasis 1996, 14, 325-334.

31. Lessan, K.; Aguiar, D.J.; Oegema, T.; Siebenson, L.; Skubitz, A.P. CD44 and $\beta 1$ integrin mediate ovarian carcinoma cell adhesion to peritoneal mesothelial cells. Am. J. Pathol. 1999, 154, 1525-1537.

32. Arroyo, M.P.; Downey, K.M.; So, A.G.; Wang, T.S. Schizosaccharomyces pombe proliferating cell nuclear antigen mutations affect DNA polymerase delta processivity. J. Biol. Chem. 1996, 271, 15971-15980.

33. Ksiazek, K.; Passos, J.F.; Olijslagers, S.; Saretzki, G.; Martin-Ruiz, C.; von Zglinicki, T. Premature senescence of mesothelial cells is associated with non-telomeric DNA damage. Biochem. Biophys. Res. Commun. 2007, 362, 707-711.

34. Luppi, F.; Longo, A.M.; de Boer, W.I.; Rabe, K.F.; Hiemstra, P.S. Interleukin-8 stimulates cell proliferation in non-small cell lung cancer through epidermal growth factor receptor transactivation. Lung Cancer 2007, 56, 25-33.

35. Liang, Y.; Brekken, R.A.; Hyder, S.M. Vascular endothelial growth factor induces proliferation of breast cancer cells and inhibits the anti-proliferative activity of anti-hormones. Endocr. Relat. Cancer 2006, 13, 905-919.

36. Cannistra, S.A.; DeFranzo, B.; Niloff, J.; Ottensmeir, C. Functional heterogeneity of CD44 molecules in ovarian cancer cell lines. Clin. Cancer Res. 1995, 1, 333-342.

37. Murias, M.; Handler, N.; Erker, T.; Pleban, K.; Ecker, G.; Saiko, P.; Szekeres, T.; Jager, W. Resveratrol analogues as selective cyclooxygenase-2 inhibitors: Synthesis and structure-activity relationship. Bioorg. Med. Chem. 2004, 12, 5571-5578.

38. Ksiazek, K.; Jorres, A.; Witowski, J. Senescence induces a proangiogenic switch in human peritoneal mesothelial cells. Rejuvenation Res. 2008, 11, 681-683.

(C) 2013 by the authors; licensee MDPI, Basel, Switzerland. This article is an open access article distributed under the terms and conditions of the Creative Commons Attribution license (http://creativecommons.org/licenses/by/3.0/). 